\title{
A apropriação social da Internet pelo bibliotecário catarinense: o retrato de uma década
}

\author{
The social appropriation of the Internet by librarians \\ in Santa Catarina: a portrait of a decade
}

Elisa Cristina Delfini CORRÊA'

\section{Resumo}

Este trabalho analisa páginas web de Unidades de Informação catarinenses a fim de conhecer a interação do bibliotecário com a Internet, por meio de sua participação na criação e na manutenção das páginas web de diferentes instituições em Santa Catarina. Pretende reavaliar o cenário catarinense uma década após pesquisa semelhante realizada pela autora em 1999. Foram elencadas dezesseis instituições, distribuídas nas seguintes categorias: industrial, empresarial, agropecuária, ciência e tecnologia, meio ambiente e universidades. Através da descrição do conteúdo da página, buscou-se identificar a menção do bibliotecário como responsável pela criação e/ou manutenção da página (de forma direta na própria página web ou indireta através da análise dos produtos e serviços oferecidos). Constatou-se que apenas duas instituições mencionam participação direta do bibliotecário na equipe responsável pelas páginas. Esses resultados reforçam os obtidos há dez anos: outros profissionais tem-se ocupado em criar as páginas web das Unidades de Informação na Internet, sendo ainda muito tímidos os sinais de apropriação social da rede como campo de trabalho A participação do bibliotecário, quando existente, não representa um avanço na apropriação da Internet nem como ferramenta nem como campo de trabalho em Santa Catarina, o que não contribui para uma maior visibilidade de sua atuação no ciberespaço.

Palavras-chave: Bibliotecário. Internet. Profissional da informação. Unidades de informação.

\begin{abstract}
Analysis of web pages by information units in the Brazilian state of Santa Catarina, with the aim of understanding the librarian's interaction with the Internet, through his/her participation in the creation and maintenance of web pages from different institutions in Santa Catarina. The study aims to reevaluate the picture in Santa Catarina a decade after a similar survey carried out by the author in 1999. Sixteen institutions were listed, divided into the following categories: Industrial Sector, Business Sector, Agricultural Sector, Science and Technology, Environment Sector and Universities. Through the description of page contents, it was sought to identify mention of the librarian responsible for the creation or maintenance of the web page (directly on the page or indirectly through an analysis of the products and services offered). It was found that only two institutions mentioned the direct participation of the team's librarian responsible for the pages. The current findings support those of ten years ago: other professionals have been busy creating web pages for the Information Unit on the Internet, still quite timid signs of social appropriation of the network as a field of work.
\end{abstract}

Keywords: Librarian. Internet. Information professional. Information units.

\section{Introdução}

Após o advento das novas tecnologias e da consequente multiplicação da quantidade e da velocidade do fluxo informacional, as maneiras convencionais de tratamento e de disseminação da informação passaram por significativas transformações, dentro e fora da Unidade de Informação (UI). O computador fundamenta hoje

\footnotetext{
1 Professora Doutora, Universidade do Estado de Santa Catarina, Centro de Ciências Humanas e da Educação, Faculdade de Educação, Departamento de Biblioteconomia e Gestão da Informação. Av. Madre Benvenuta, 2007, Itacorubi, 88035-001, Florianópolis, SC, Brasil. E-mail: <correa.net@uol.com.br>.

Recebido em 12/4/2011, reapresentado em 4/7/2011 e aceito para publicação em 8/9/2011.
} 
grande parte das atividades práticas dos bibliotecários em qualquer que seja a área de sua atuação. A partir desse aparato tecnológico, são verificadas profundas transformações nas maneiras de criar, buscar, difundir e utilizar a informação. Prova mais contundente disso é a Internet, através da qual flui uma quantidade quase ilimitada de informações e dados dos mais variados temas.

São grandes os desafios colocados ao bibliotecário: profissional dedicado à organização, processamento e disseminação da informação. A ele são atribuídas funções específicas direcionadas à utilização de técnicas para o tratamento adequado da informação, a fim de satisfazer as necessidades informacionais de seus usuários.

O papel de mediador da informação agora precisa ser adaptado a um usuário muito familiarizado com essas tecnologias. Os usuários da informação apresentam-se progressivamente mais "íntimos" das Novas Tecnologias de Informação e Comunicação (NTIC), utilizando intensamente os recursos da Internet e apresentando demandas cada vez mais específicas e urgentes de informação. Como resultado mais direto, os bibliotecários vêm adequando sua prática profissional ao novo paradigma informacional, principalmente através de capacitação especializada em questões que envolvem as NTIC. No que diz respeito aos quesitos eficiência e rapidez, os usuários de informação científica e tecnológica, bem como de áreas cuja competitividade de mercado se apresenta de modo mais acirrado, têm necessidades de informação que precisam ser supridas de forma precisa e urgente. Para que isso aconteça, é necessário haver não apenas UI bem equipadas, mas também - e principalmente - profissionais competentes e atualizados.

Essa nova postura representa não apenas uma forma de adaptação aos novos tempos, mas algo também extremamente necessário para a sobrevivência do profissional no mercado de trabalho, uma vez que, juntamente com a proliferação de novos equipamentos e produtos tecnológicos, proliferam também novas categorias e profissões que se propõem a trabalhar a informação em seu formato eletrônico.

Desde a introdução do computador nas rotinas das bibliotecas, verifica-se um quase sem número de pesquisas e artigos publicados que analisam seu uso, suas potencialidades e as posturas recomendáveis ao bibliotecário diante das NTIC.
As possíveis aplicações da informática no ambiente da biblioteca, as vantagens e desvantagens da informação e da comunicação eletrônicas, as mudanças sofridas na geração, no uso e no fluxo da informação, os novos suportes, as alterações e as atualizações curriculares dos cursos de biblioteconomia na tentativa de acompanhar os avanços tecnológicos e as redes sociais são temas constantes de pesquisa. As tecnologias estão, portanto, na pauta das discussões e de muitos projetos na área há vários anos e não são mais nenhuma novidade para os profissionais atuantes em diferentes UI.

Com a finalidade de investigar a maneira como os bibliotecários em Santa Catarina lidavam com a questão da informação no mundo digital - mais especificamente na Internet -, foi realizada uma pesquisa para dissertação de mestrado no ano de 1999, que buscava conhecer e analisar os usos da Internet, monitorados pelo profissional bibliotecário, no ambiente de oito UI catarinenses. Na ocasião, concluiu-se que essa interação representava uma fase de transição entre antigos e novos paradigmas, e verificou-se que ainda são muito fortes os papéis desempenhados pelo profissional mais tradicional.

À época, constatou-se que a apropriação social da Internet estava apenas em sua fase inicial, caracterizada por usos superficiais dos recursos da rede. No entanto, já era possível identificar casos isolados de participação mais arrojada na construção das infovias. Constatou-se, também, a intervenção de outras categorias de profissionais no trabalho de gestão da informação digital e na criação de bibliotecas virtuais.

Revisitar esse cenário e reavaliar esse quadro em Santa Catarina, uma década depois do primeiro estudo, é a proposta do presente trabalho de pesquisa. A princípio, buscou-se investigar as mesmas instituições pesquisadas em 1999. O objetivo principal era demarcar e analisar os usos atuais da Internet, monitorados pelo profissional bibliotecário no ambiente da UI, de forma comparativa aos usos revelados há 10 anos, com a finalidade de apresentar um retrato do atual estado da arte. As instituições que constituíram o universo da pesquisa em 1999 seriam novamente visitadas para compor o retrato atualizado dos usos feitos da Internet.

No entanto, verificou-se, em 2009, uma significativa diminuição da população-alvo da pesquisa. Das oito instituições analisadas na década de 1990, três extinguiram a 
Ul e uma não tinha (à época da coleta de dados) bibliotecário em seu quadro de pessoal, reduzindo para apenas 4 o número de instituições a serem pesquisadas. Dessa forma, o universo da pesquisa apresentou-se não representativo para o alcance proposto inicialmente: demonstrar a interação com a rede, como campo de trabalho pelo bibliotecário atuante, em UI que trabalham com informação científica e tecnológica no Estado.

Fez-se necessária a readequação da metodologia e da proposta de investigação, que resultou no seguinte questionamento: é possível reconhecer o nível de interação do bibliotecário com a Internet através de sua participação na criação/manutenção das páginas web das UI das principais instituições de Ciência e Tecnologia (C\&T) em Santa Catarina? Essa interação poderia representar uma efetiva apropriação social dessa tecnologia ou ainda podem ser visualizados sinais de desintermediação, com identificação de lacunas sendo preenchidas por diferentes profissionais da informação?

O objetivo principal desse novo direcionamento de pesquisa assemelha-se ao primeiro, uma vez que buscou conhecer a interação do bibliotecário catarinense com a Internet através de sua participação na criação e na manutenção das páginas web das UI de instituições catarinenses em C\&T, a fim de detectar sinais de apropriação social ou de desintermediação desse profissional no uso da Internet.

No entanto, o questionamento segue um pouco além, procurando reconhecer nessa participação uma visualização mais direta da atuação desse profissional em termos de informações disponibilizadas digital ou virtualmente ao público em geral que utiliza os serviços dessas páginas. A indicação da participação do bibliotecário na criação e na manutenção das páginas web de suas UI deixaria claro ao seu interagente a apropriação de ferramentas tecnológicas no exercício de sua profissão.

A base teórica da primeira pesquisa apoiou-se no conceito de desintermediação utilizado por Lévy (1993). Para o autor, a partir do advento da Internet, o contato entre produtores e consumidores da informação passou a ser feito diretamente, sem a necessidade de intervenção dos chamados "mediadores" da informação. Correa (1999, p.136) afirma que"a partir do momento em que esse contato se instala, as profissões anteriormente encarregadas de fazer a ponte entre os dois polos correm o risco de se transformar no que Lévy (1993, p.63) chama de 'intermediários parasitas da informação"'.

Lévy (1993, p.63) considera que apenas sobreviverão e prosperarão no ciberespaço as profissões que efetuarem sua "migração de competências para a organização da inteligência coletiva e do auxílio à navegação".

Desde a publicação da obra de Pierre Lévy, em 1993, o próprio ciberespaço sofreu diversas mutações, baseadas na proposta de interação direta e parceria produtor-consumidor na criação do conteúdo da Internet. A partir dessa concepção da necessidade de apropriar-se desse novo universo para a sobrevivência e pertinência das UI na sociedade contemporânea, verificou-se um aumento significativo de páginas web relacionadas à bibliotecas de diferentes categorias: oportunidade ímpar para o bibliotecário mostrar sua capacidade de "migrar competências".

Blattmanne Rados (2000, p.76) apontam a presença das bibliotecas públicas na Internet, e, em sua análise, afirmam que:

O fato de inúmeras bibliotecas públicas, principalmente em países de alta tecnologia, estarem conectadas a Internet proporciona reflexões de como apropriar novas tecnologias da informação para o acesso, o manuseio e a disseminação do conhecimento, as rupturas que ocorrem nas estruturas organizacionais, e, principalmente as novas habilidades que o bibliotecário necessita dominar para utilizar adequadamente os recursos existentes, proporcionando serviços e produtos aos usuários. Aos bibliotecários compete harmonizar um ambiente que proporcione e facilite o acesso da informação, seja na aquisição de fontes significativas e/ou também de recursos das novas tecnologias da informação para que a comunidade possa desenvolver-se educacional e culturalmente.

Bertholino et al. (2000, p.3) analisam sites de bibliotecas universitárias (BU) e discorrem sobre o futuro das bibliotecas, defendendo que essas devem buscar'caminhos inovadores para prover acesso à informação e materiais não disponíveis localmente [...]'. Mencionam também um estudo no qual foram identificadas as 10 profissões do futuro, destacando-se dentre elas o bibliotecário do ciberespaço. Ainda, segundo Bertholino et al. (2000, p.3), o trabalho desses profissionais consiste '[...] em saber onde cada tipo de informação está disponível 
na Internet para poder orientar seus clientes. Para se manterem atualizados, esses profissionais compartilham informações sobre sites úteis na web e em outros locais da rede'.

Ainda sobre a presença de BU na Internet, Andrade et al. (2002, p.9) analisaram páginas web de bibliotecas de Instituições de Ensino Superior (IES) em Minas Gerais e constataram que:

Predominam nos sites pesquisados informações relativas à própria biblioteca, seu horário de funcionamento e as formas de entrar em contato com elas. São também apresentadas relações dos serviços executados e dos materiais que compõem os acervos. De modo geral, observa-se que os sites se aproximam, quanto ao conteúdo, dos guias impressos de bibliotecas [...]. A pre-sença de atividades de renovação e reservas de obras do serviço de empréstimo parece indicar a tendência de se prestar serviços on-line quando os mesmos permitirem. Essa tendência também pode ser observada em relação ao acervo ao se incluírem lista dos títulos que compõem a coleção de periódicos e acesso a base de dados. Ao criarem links as bibliotecas revelam que compreendem bem o que é um website e o meio em que este é projetado e mantido. Entretanto, a geração desse produto demanda critérios cuidadosos de seleção para garantir um bom nível de qualidade e, assim, o atendimento às necessidades de informação de seus usuários .

Não é sem razão que as BU são objeto da maioria dos estudos na área, já que são mais frequentemente encontradas em páginas web. No entanto, mesmo elas ainda são passíveis de análises críticas que demonstram que o caminho a ser trilhado para sua excelência na rede ainda é longo. Conforme Guedes (2002, p.14), 'é preciso introjetar o compromisso de mudança e o senso de urgência'.

Em todas as citações acima, percebe-se com clareza a responsabilidade do bibliotecário na veiculação de informações através de páginas de bibliotecas na Internet. Sejam explícitas ou implícitas as recomendações encontradas na literatura, a atuação desse profissional poderá ser fator preponderante no sucesso da oferta de produtos e serviços de informação na rede.

Apesar do aumento significativo da presença da Internet na prática de trabalho do bibliotecário, seus usos ainda podem ser considerados superficiais, pois se baseiam em ferramentas como o correio eletrônico e busca em recursos da rede de maneira geral. Em outras palavras, não ultrapassam os usos da maioria das pessoas na sociedade contemporânea.

A dissertação de mestrado de Corrêa (1999) aponta a necessidade de uma nova visão da Internet por parte da classe bibliotecária: a apropriação social da rede não apenas como ferramenta de trabalho, mas, sim, como campo de atuação. Nesse aspecto em especial,'os bibliotecários precisam perceber que sua melhor esperança reside no trabalho com os vendedores na estruturação de ferramentas para a distribuição de informação. Bibliotecários podem auxiliar a desenhar e a implantar os novos sistemas'.

Corrêa (1999, p.128) também afirma que a Internet, para os bibliotecários entrevistados, "não se constitui uma ameaça à profissão. Ela é considerada única e exclusivamente como uma ferramenta a mais a ser utilizada no desempenho de suas funções. Essa concepção tanto expande a atuação do bibliotecário nos moldes tradicionais quanto limita sua migração para a categoria de cibertecários".

Essa migração de competências se traduz no que Rodrigues (1996) analisa como a emergência de uma nova classe dentro da biblioteconomia: os cibertecários, que são os bibliotecários de um futuro que já chegou. Segundo o autor, a atuação do cibertecário vai além da função de facilitar o acesso à informação eletrônica. Ele deverá ser também o responsável pela organização das chamadas "autoestradas" da informação, cuja utilização dependerá de mapas, guias e roteiros, áreas de serviço e controladores do tráfego de informação.

Além de Rodrigues, vários outros autores da área de Biblioteconomia e Ciência da Informação são categóricos em afirmar a necessidade de uma inserção efetiva nas questões da informação digital/virtual/eletrônica e constante qualificação nessa área; caso contrário, o bibliotecário encontrará grandes dificuldades em firmar-se profissional atuante e necessário em nossa sociedade altamente competitiva. Dentre eles, podem ser mencionados Tarapanoff (1989, p.106), para quem "o volume da informação e as novas tecnologias obrigam hoje o bibliotecário a repensar o seu perfil profissional e o seu papel no mercado da informação"; e Giannasi et al. (1995, 
p.173), que também menciona que, a partir das NTIC, verifica-se um novo cenário que'exige uma nova postura profissional'.

Aquino (2004, p.9) aponta o fato de que "as conexões da informática com a telemática têm sido responsáveis pelo surgimento da informação em diferentes formatos de acesso e uso dessa informação. A passagem da cultura impressa para a cultura digital afetou não apenas os ambientes do papel, exigindo-lhes não só sua adequação aos novos formatos, mas impondo a aquisição de novas competências e habilidades para o desenvolvimento dos serviços informacionais".

Sendo assim, torna-se notória a necessidade do desenvolvimento do bibliotecário em sua relação com a informática e de uma habilidade específica para a manipulação da informação em meio eletrônico. No entanto, apesar das constatações teóricas dessa urgente necessidade de adaptação, interessa saber se a prática profissional corresponde às condições indicadas nos diversos artigos sobre o tema, afastando assim os perigos de uma "desintermediação" no contexto catarinense.

Para contrapor o conceito acima descrito, a pesquisa recorre também ao conceito de "apropriação social da técnica", que significa"o processo de domínio de equipamentos por parte de grupos que se tornam aptos a gerir o uso dos mesmos" (Benakouche, 1995, p.57).

Benakouche (1995, p.57) apresenta o conceito e afirma que se trata de "uma noção certamente indispensável no estudo das implicações sociais de qualquer inovação técnica" e explica que se entende por essa expressão "o processo de aprendizado/domínio dos diferentes grupos sociais com relação aos usos dos objetos técnicos a que têm acesso". A autora argumenta que os níveis e as maneiras com as quais diferentes grupos sociais se apropriam da técnica variam de acordo com sua experiência, seu propósito, sua história e seu contexto social:

Em geral a apropriação social de uma inovação faz-se de forma diferenciada entre sociedades e entre grupos de uma mesma sociedade. Esta observação contraria a crença - mais difundida do que seria desejável - de que uma vez disponíveis no mercado, as inovações teriam as mesmas implicações em todos os lugares, ou seja, que seus usuários desenvolveriam universalmente as mesmas práticas (Benakouche,1995, p.57).
Assim sendo, pode-se afirmar que a maneira como as tecnologias são entendidas e a apropriação social (usos) que delas é feita são fatores essenciais para que a desintermediação se torne ou não um fato consumado na profissão do bibliotecário. Corrêa (1999) faz uma retrospectiva histórica da relação entre biblioteconomia e NTIC, lembrando que sua primeira forma de apropriação dessas tecnologias foi através da chamada "automação de bibliotecas", transpondo para o computador as tarefas de catalogação feitas manual e isoladamente até então.

A partir daí, vieram as bases de dados, as bibliotecas digitais e virtuais, e, aos poucos, todos os serviços e produtos de uma UI tornaram-se passíveis de realizar-se através do computador e da conexão com a Internet. No entanto, para intervir no processo de virtualização da informação, tornando-se agente construtor das chamadas "infovias", o bibliotecário deve ser capaz de intergir com a máquina, falar sua linguagem e saber não apenas usá-la, mas criar a partir dela. Em outras palavras: apropriar-se socialmente dessa tecnologia.

Enfim, para Corrêa (1999, p.57), parecia faltar "ao bibliotecário atuante no mercado de trabalho em Santa Catarina a ampliação de sua visão em relação às oportunidades oferecidas pela Internet, para que sua participação na rede ultrapassasse a de 'usuários que auxiliam outros usuários'na pesquisa de seu potencial informativo".

Uma década mais tarde, buscou-se repetir os procedimentos de pesquisa para configurar o retrato atual dessa interação bibliotecário/Internet no Estado. Contudo, a partir das dificuldades já apontadas nesta introdução, fez-se necessário criar novas formas e metodologias de coleta e análise de dados a fim de atingir os seguintes objetivos:

- Verificar a existência do profissional bibliotecário nas equipes de criação e manutenção das páginas web;

- Investigar as atribuições desse profissional na alimentação da página;

- Identificar a participação do bibliotecário nas atividades ligadas à disponibilização de informações da e pela Ul em formato eletrônico.

O conhecimento e a utilização de ferramentas de informática voltadas ao tratamento e disseminação da informação na atualidade são pré-requisitos essenciais para a atuação do bibliotecário na sociedade contem- 
porânea. Em 1999, quando a primeira pesquisa foi realizada, a introdução de equipamentos de informática no ambiente das bibliotecas e centros de documentação ainda se encontrada em estágios iniciais.

Decorridos dez anos, a democratização da informática superou as expectativas: a situação hoje verificada ultrapassa em muito as condições encontradas na pesquisa de mestrado. A introdução das prerrogativas da web 2.0 e 3.0 ampliou potencialmente a participação dos usuários em interferir na geração do conteúdo da rede, e o cenário atual apresenta uma infinidade de informações veiculadas através de diferentes formatos e mídias em diferentes tipos de fontes de informação que não prescindem, necessariamente, da presença do bibliotecário em sua organização.

No entanto, é preciso saber se os bibliotecários em atuação no contexto catarinense estão efetivamente se apropriando dessas tecnologias para o desempenho do trabalho informacional, que depende não apenas da formação do profissional, mas também das condições oferecidas pelas instituições às quais as UI estão vinculadas e, principalmente, de uma busca pessoal por qualificação.

Como visto, é muito frequente na literatura específica da área encontrar recomendações dirigidas ao bibliotecário para que ele aprofunde seus conhecimentos e técnicas de trabalho no ambiente digital e virtual. Ao longo dos últimos anos, percebe-se esse esforço por parte de toda a categoria, especialmente nas recorrentes atualizações curriculares dos cursos de graduação a partir de um enfoque voltado às questões tecnológicas. Para saber se isso ocorre na prática, no entanto, faz-se necessário utilizar estratégias de pesquisa para reconhecer sinais dessa efetiva apropriação tecnológica na rotina desse profissional.

O foco da presente pesquisa repousa sobre as páginas web de UI que já existem fisicamente em Santa Catarina. O objeto da análise retrata, sob o ponto de vista da pesquisadora, uma das tarefas mais básicas das quais o bibliotecário pode participar ativamente dentro do ciberespaço: a criação e a manutenção de homepages de suas UI. A partir dessa proposta, é possível visualizar um dos diversos caminhos que podem ter sido traçados pelos profissionais no período de dezanos, investigar a evolução dos usos da Internet no ambiente de trabalho e detectar as possíveis migrações sugeridas em 1999 dentro do espectro de análise pretendido.

A presente proposta apoiou-se também em pesquisa de mestrado feita por Paz (2000), que focou sua análise em páginas web de BU a fim de conhecer quais informações são ali disponibilizadas e a forma como são apresentadas e mantidas. A pesquisa realizada por Paz deu-se através de dados coletados em questionários enviados às instituições às quais as bibliotecas pertencem, com enfoque nos seguintes aspectos das páginas web de 189 IES: dados de identificação institucional; dados sobre a biblioteca; caracterização da informação disponibilizada; dados sobre a criação e a manutenção das informações.

No entanto, chamou a atenção um dos itens pesquisados dentro do último aspecto acima mencionado, básico para a presente investigação: a participação do bibliotecário na manutenção das informações disponibilizadas nas homepages analisadas. Os resultados ali apresentados apontam uma"participação dos bibliotecários [...] na maioria das vezes de maneira indireta, embora esses demonstrem grande interesse pela questão" (Paz, 2000, p.ix).

O grande interesse do bibliotecário em articular-se profissionalmente no campo de trabalho voltado à informação veiculada pela Internet deveria ser verificado através das atividades mais básicas nessa área: disponibilizar informações da e sobre a biblioteca através de suas homepages. A partir desse pressuposto, desenvolveu-se a presente pesquisa.

Sendo assim, para saber se tais informações são disponibilizadas nas homepages de bibliotecas em Santa Catarina, foram elencadas 16 páginas web para análise desse quesito em especial. Os dados coletados, além de permitirem uma composição do retrato atual da atuação do profissional catarinense, permitiram também uma reflexão que pode contribuir para que a Universidade do Estado de Santa Catarina, como formadora e capacitadora dessa categoria profissional, possa refletir suas práticas de ensino, pesquisa e extensão, na direção de uma biblioteconomia cada vez mais atualizada e coerente com a sociedade contemporânea.

\section{Métodos}

Pesquisa de natureza aplicada que se configura como aquela que gera conhecimentos com vistas à 
solução de problemas específicos. Constitui-se, segundo seus objetivos, como descritiva e exploratória na medida em que procurou descortinar os caminhos dos profissionais atuantes nas Ul em Santa Catarina através da análise de suas páginas web. O universo de pesquisa foi composto por 16 páginas de bibliotecas vinculadas a instituições ligadas a 5 áreas de atuação e pesquisa:

- Área: Agricultura: Epagri: <http://www.epagri. sc.gov.br/index.php?option=com_wrapper\&view $=$ wrapper\&ltemid=37>;CCA/UFSC: $<$ http://www.bu. ufsc. br/b scca/>; Embrapa - Btca. Suínos e Aves - Concórdia: $<$ http://www.cnpsa.embrapa.br/>.

- Área: Empresarial/Industrial: Sebrae: <http:// www.sebraesc.com.br/biblioteca/default.asp>; Senai: $<$ http://biblioteca.sc.senai.br/pergamum/biblioteca/ index.php>.

- Área: Educação Superior:UDESC: <www.bu.udesc. br>; UFSC: <www.bu.ufsc. br>; IF-SC: <http://biblioteca. ifsc.edu.br/sophia/>; UNIVALl: <http://www.univali.br/ modules/system/stdreq.aspx?P=197\&VID=default\& $S I D=235831333234329 \& S=1 \& A=$ closeall\&C$=24252>$; UNISUL: <http://portal2.unisul.br/content/site/biblioteca /index.cfm>. UNOESC: <http://www.unoesc.edu.br/ biblioteca>; UNIVILLE: <http://community.univille.edu.br/ biblio teca_universitaria>.

- Área: Ciência e Tecnologia: CIASC: <http:// www.ciasc.gov.br/index.php?option=com_content\& view $=$ article\&id=36\&ltemid=38>; SESI - SAPIENS PARK: $<$ http://bibliotecasesi sapiensparque.blogspot.com/>.

- Área: Meio Ambiente: Secretaria do Estado de Desenvolvimento Econômico Sustentável: <http://www. sds.sc.gov.br/index.php?option=com_docman \&ltemid $=46 \&$ lang=brazilian_portuguese $>$; FATMA: $<$ http $: / /$ www.fatma.sc.gov.br/index.php?option=com_content \&task=view\&id=61\&ltemid $=140>$.

A escolha dos sites analisados deu-se a partir das áreas cobertas pela primeira pesquisa, realizada em 1999, a saber²: Setor industrial; Setor empresarial; Setor agropecuário; Setor ciência e tecnologia; Setor meio ambiente; Universidades.

O levantamento dos sites levou em consideração os seguintes critérios:
- Utilização dos termos definidos como áreas enquanto palavras-chave no buscador Google;

- Instituições sediadas no Estado de Santa Catarina;

- Existência de links para a biblioteca na página inicial da instituição ou de página própria da UI na Internet.

A análise dos sites constituiu-se de:

- Descrição do conteúdo da página a fim de identificar os tipos de informação e serviços oferecidos pelas Ul disponíveis no site;

- Identificação do profissional bibliotecário presente na UI (caracterizada de forma explícita ou implícita, através de produtos e serviços nos quais o profissional é indispensável);

- Identificação do bibliotecário enquanto responsável pela criação e/ou manutenção da página (de forma direta ou indireta através da análise dos produtos e serviços oferecidos).

Os dados coletados foram analisados de forma qualitativa e quantitativa e apresentados através de gráficos acompanhados das devidas considerações, que visam ao aprofundamento da questão proposta pela análise.

\section{Resultados e Discussão}

A partir da leitura analítica das páginas web elencadas, foi possível detectar os sinais da participação do bibliotecário na versão eletrônica das bibliotecas das dezesseis instituições catarinenses. A fim de atingir os objetivos gerais e específicos propostos, levantaram-se informações que atendessem os questionamentos que nortearam a pesquisa. Os dados coletados foram agrupados e analisados dentro de três categorias específicas: descrição do site; identificação da participação direta do bibliotecário e identificação da participação indireta do bibliotecário.

Essas categorias foram criadas com a finalidade de localizar e coletar dados que possibilitassem a construção do quadro atual da participação desse profissional em Santa Catarina, permitindo assim uma análise da

\footnotetext{
2 Para fins de agrupamento dos sites, os setores industrial e empresarial fundiram-se em uma única área, e o setor universidades passou a denominar-se educação superior. No entanto, todos estão contemplados na pesquisa.
} 
evolução da interação com a Internet, evidenciada a partir da criação e da manutenção de páginas de UI na Internet.

Das páginas das instituições pesquisadas, não foi possível identificar a presença de todos os critérios analisados em nenhum dos sites. Algumas características especiais podem ser apontadas:

- Três páginas abrem diretamente na interface de pesquisa da base de dados utilizada pela instituição, não apresentando nenhuma outra informação adicional;

- Uma página configura-se como um blog, apesar de autodenominar-se "biblioteca";

- As páginas das instituições voltadas ao ensino apresentaram o maior número das informações requeridas nos critérios elencados.

Essas particularidades, no entanto, não trazem prejuízo à análise, apenas apresentam características diferenciadas do universo analisado. Todas as 16 páginas formam o conjunto da amostra, que representa as áreas elencadas para análise, tendo sido esse universo pesquisado em sua totalidade.

\section{Descrição do site}

A exemplo da pesquisa de Paz (2000), consideraram-se importantes para este estudo descrever e analisar os tipos de informação disponíveis. O objetivo, no entanto, era buscar reconhecer o tipo de informação diretamente relacionada com as atividades típicas do bibliotecário na UI. Sendo assim, esse item apresenta duas subcategorias: tipos de informação disponível na página e serviços disponíveis. Dentro dessas subcategorias são analisadas tanto a participação direta quanto as possibilidades indiretas de participação do bibliotecário na inserção e na manutenção de informações na homepage.

- Tipos de informação disponível: são listados aqui os itens constantes nas páginas das UI, como informações de contatos, links e notícias diversas.

A maioria dos sites analisados fornece informações básicas referentes à UI física, indicando endereços e telefones para contato, horários e dias de funcionamento, e informações sobre a missão e objetivos da UI (Figura 1).

Apenas 5 páginas indicaram responsabilidade pela criação e manutenção do site. Dessas, 2 apontam a presença de um bibliotecário como parte integrante da equipe responsável; as demais indicam empresas que prestam serviços de criação de sites e os setores de informática da instituição (Figura 2).

A maioria das páginas analisadas oferece acesso a sistemas de bases de dados que contêm informações sobre o acervo físico da UI (Figura 3). A única que não oferece esse serviço é a UI cuja página é um blog no qual são postados textos relativos a leituras e obras literárias. Nesse item fica implícita a presença do profissional, uma vez que se pressupõe que um bibliotecário ou uma equipe desses profissionais sejam os responsáveis pela introdução dos dados, o que, por sua vez, exige técnica e treinamento específicos da profissão.

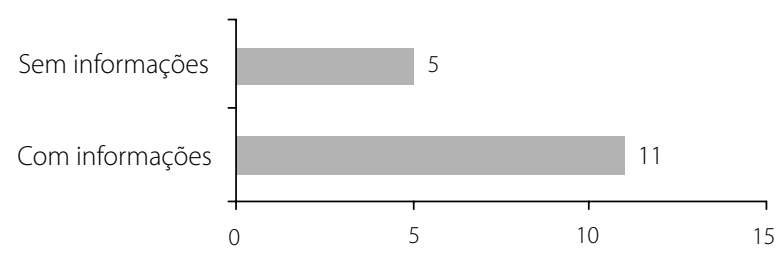

Figura 1. Informações da unidade de informação.

Fonte: Elaborado pela autora.

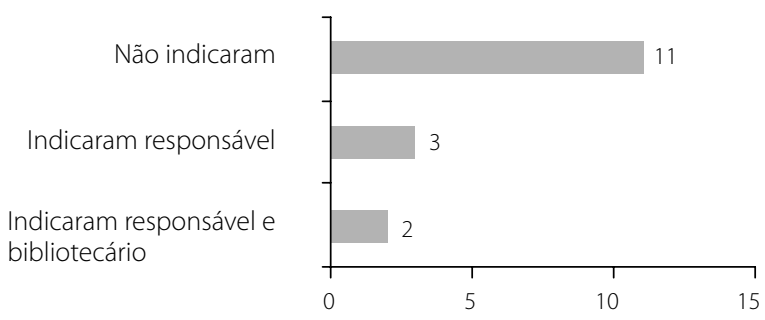

Figura 2. Responsabilidade da página.

Fonte: Elaborado pela autora.

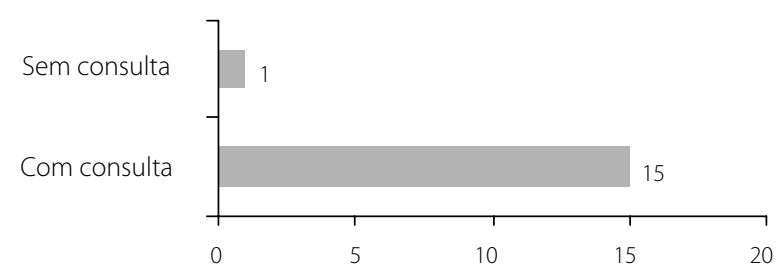

Figura 3. Base de dados de consulta ao acervo físico.

Fonte: Elaborado pela autora. 
A partir da coleta de dados específicos sobre a responsabilidade desse profissional na inserção e manutenção de dados da página, foram analisadas as informações sobre sua participação a partir de duas possibilidades: menção direta dessa atuação e indireta através de produtos e serviços de informação característicos do fazer bibliotecário (Figura 4).

Apenas 2 das 16 páginas analisadas incluem 0 bibliotecário ou a equipe da biblioteca como parte integrante na responsabilidade de criação e manutenção do site; as demais páginas ou não informam ou creditam a criação e a manutenção de suas páginas ou aos setores de informática da instituição ou às empresas prestadoras de serviços de webdesign.

A participação indireta do bibliotecário na gestão do conteúdo das páginas corresponde aos serviços encontrados em 4 das 16 páginas web analisadas. Através das atividades de consultas por e-mail, informativo virtual, sumários eletrônicos, levantamento bibliográfico, alerta, resposta técnica, solicitação de catalogação na fonte, é possível supor que o staff da biblioteca participe da

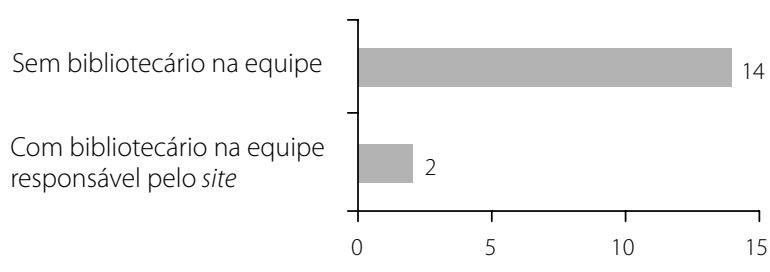

Figura 4. Participação direta do bibliotecário.

Fonte: Elaborado pela autora.

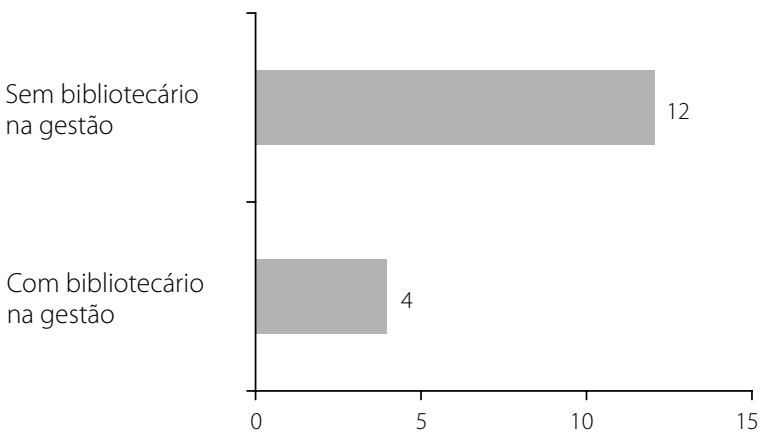

Figura 5. Participação indireta do bibliotecário.

Fonte: Elaborado pela autora. alimentação de dados acessíveis através dos sites das UI, no entanto não é possível afirmar o tipo de participação do profissional, que pode ter atuado como coordenador ou executor das atividades (Figura 5).

\section{Conclusão}

Os dados aqui coletados e analisados representam apenas a "ponta do iceberg", um simples retrato visível a qualquer pessoa que porventura acesse a página de uma das UI que foram objeto da pesquisa. Essa visualização, no entanto, é fundamental para demonstração imediata da presença do bibliotecário na Internet através da apresentação das homepages de importantes instituições de pesquisa e tecnologia em Santa Catarina.

Esse primeiro contato visível poderia representar ao público em geral uma nova concepção do bibliotecário atual, contribuindo para a ruptura com o estereótipo do profissional que atua apenas dentro da UI física e trabalha apenas com acervos impressos. No entanto, os resultados obtidos demonstram que, sob esse ponto de vista, a participação do bibliotecário, quando existente, na criação e na manutenção das páginas web das UI pesquisadas não representa exatamente um avanço na apropriação do uso da Internet nem como ferramenta e muito menos como campo de trabalho desse profissional em Santa Catarina.

Ao longo de 10 anos decorridos desde o primeiro estudo, alguns fatores que fazem parte do histórico da presente pesquisa podem ser considerados sintomáticos quanto à ainda premente necessidade de uma apropriação social da Internet mais efetiva.

Em primeiro lugar, está a própria necessidade de modificar a metodologia da pesquisa decorrente da diminuição do universo em relação ao estudo de 1999. A desativação de 3 das 8 unidades pesquisadas e a ausência do bibliotecário em uma delas reduziram pela metade o universo a ser estudado, provando que, para essas instituições, nem mesmo a UI foi capaz de sobreviver às mudanças sociais ocorridas durante o período.

Em segundo lugar, os resultados obtidos demonstram que, apesar da presença evidente do bibliotecário na maioria das instituições pesquisadas, a criação e a manutenção das páginas web de sua UI não dependem 
diretamente da intervenção desse profissional. A não ser pelas duas únicas menções diretas feitas ao bibliotecário como membro da equipe responsável pela página, nas demais não é possível afirmar a atuação desse profissional em sua criação ou manutenção.

Muito implicitamente, a relação mais direta que se pode fazer entre o conteúdo informacional das páginas e o bibliotecário reside na alimentação das bases de dados que oferecem acesso aos acervos físicos que as UI apresentam. Apesar da necessidade de adaptar as técnicas bibliotecárias para a alimentação desses dados, esse fato não se caracteriza como uma apropriação social da Internet propriamente dita, e, portanto, não pode ser considerado como argumento a favor na análise aqui realizada.

Sendo assim, conclui-se que a interação do bibliotecário com a Internet no que diz respeito à criação e à manutenção das páginas web das UI pesquisadas não representa um avanço significativo na apropriação social dessa ferramenta. Parece até mesmo redundante afirmar que o bibliotecário em atuação no mercado de trabalho contemporâneo que deixa de fazer uso do computador para desenvolver sua profissão corre sérios riscos de se transformar em peça obsoleta nesta sociedade altamente digitalizada. No entanto, ao mesmo tempo em que não há duvidas de que são muitos os avanços na formação e atuação bibliotecária em termos da produção de serviços e desenvolvimento de produtos de informação com base em ferramentas tecnológicas, também é verdadeiro o fato de que nem sempre é visível a participação desse profissional nas páginas web nas quais essas informações encontram-se disponíveis.

Dentre as diversas explicações possíveis, reúne-se um conjunto de variáveis que devem ser consideradas quando esse é o assunto em questão. Dentre elas, podese mencionar uma ainda tímida valorização institucional do bibliotecário como profissional responsável pela criação e pela manutenção das páginas institucionais de suas UI. Deixa-se essa tarefa sob a responsabilidade de profissionais da área da informática e não se oferece ao bibliotecário o devido espaço de criação. Porém, pode- -se encontrar uma igualmente tímida disposição do profissional em aderir ao movimento tecnológico e desenvolver suas habilidades e competências profissionais no mundo digital. Dessa forma, o bibliotecário também não reivindica esse espaço, que acaba sendo ocupado por outros profissionais da informação.

Uma terceira possibilidade é a de que o bibliotecário atuante nas Ul exerça também as funções de criação e de manutenção da página web, sem, no entanto, divulgar essa atuação, não ficando claro ao pesquisador sua participação no processo. As possíveis explicações, na verdade, transformam-se em novas possibilidades para futuros estudos.

Os dados obtidos na pesquisa apenas reforçam os resultados obtidos há 10 anos: outros profissionais têm-se ocupado em criar mesmo os produtos mais básicos que uma UI pode oferecer na Internet. Os bibliotecários, pelo ponto de vista abordado nesta análise, ainda exercem com mais frequência as suas funções tradicionais dentro do ambiente físico da biblioteca.

Quase a totalidade das informações contidas nas páginas analisadas depende dessa atuação técnica do bibliotecário, mas nenhuma delas representa efetivamente uma atuação tecnológica desse profissional e, portanto, não se pode afirmar que o atual estado da arte em Santa Catarina apresente sinais mais evidentes de uma apropriação social da Internet como campo de trabalho do bibliotecário.

Se essa constatação se faz verdadeira na análise de sites institucionais de UI, nos quais deveria ser mais natural a intervenção desse profissional, permanece a questão em aberto para análise em outros tipos de páginas web, nas quais os bibliotecários poderiam atuar como criadores das "infovias" do ciberespaço. Os resultados aqui apresentados e discutidos significam um recorte de estudos dentro de uma profissão que tem um amplo leque de possibilidades de atuação, formando um verdadeiro mosaico montado de diferentes facetas profissionais. Em outras palavras, ainda há muito a avançar em termos de pesquisas nessa área.

\section{Referências}

ANDRADE, M.E.A. et al. Biblioteca universitária em meio digital: análise das bibliotecas dos cursos de direito em Minas

Gerais. In: SEMINÁRIO NACIONAL DE BIBLIOTECAS UNIVERSITÁRIAS, 13., 2002, Natal. Anais eletrônicos... Disponível em: 
<http://www.sibi.ufrj.br/snbu/snbu2002/oralpdf/95.a.pdf>. Acesso em: abr. 2010.

AQUINO, M.A. Metamorfoses da cultura: do impresso ao digital, criando novos formatos e papéis em ambientes de informações. Ciência da Informação, v.33, n.2, p.7-14, 2004. Disponível em: <http://revista.ibict.br/index.php/ciinf/article/ view/504/458>. Acesso em: 10 mar. 2009.

BENAKOUCHE, T. Novas tecnologias de comunicação: realidades e mitos. Universidade e Sociedade, v.5, n.9, p.55-59, 1995

BERTHOLINO, M.L.F. A web como canal de divulgação de serviços e produtos de bibliotecas universitárias: análise do conteúdo de home pages. In: SEMINÁRIO NACIONAL DE BIBLIOTECAS UNIVERSITÂRIAS, 11., 2000, Florianópolis. Anais eletrônicos... Disponível em: <snbu.bvs.br/snbu2000/docs/pt/ doc/t003.doc>. Acesso em: 10 mar. 2009.

BLATTMANN, U.; RADOS, G.J.V. Bibliotecas públicas na internet: serviços e possibilidades. Revista ACB: Biblioteconomia em Santa Catarina, v.5, n.5, 2000. Disponível em: <http://revista. acbsc.org.br/index.php/racb/article/view/345/410>. Acesso em: abr. 2010.

CORRÊA, E.C.D. O uso da Internet pelo bibliotecário em Santa Catarina: apropriação social ou desintermediação? 1999. Dissertação (Mestrado em Sociologia Política) - Centro de
Filosofia e Ciências Humanas, Universidade Federal de Santa Catarina, Florianópolis, 1999.

GIANNASI, M.J.et.al. O uso de novas tecnologias de informação nos cursos de Biblioteconomia da região Sul do Brasil. Revista de Biblioteconomia de Brasília, v.19, n.2, p.167-190, 1995.

GUEDES, J.B. Catálogos online: disponibilização das bibliotecas universitárias brasileiras. In: SEMINÁRIO NACIONAL DE BIBLIOTECAS UNIVERSITÁRIAS, 13., 2002. Anais eletrônicos... Disponível em: <www.sibi.ufrj.br/snbu/snbu2002/oralpdf/ 70.a.pdf>. Acesso em: 10 mar. 2010.

LÉVY, P. As tecnologias da inteligência: o futuro do pensamento na era da informática. Rio de Janeiro: Edições 34, 1993.

PAZ, C.M.M. Caracterização das informações de bibliotecas universitárias brasileiras na internet. 2000. Dissertação (Mestrado em Ciência da Informação e Documentação) - Departamento de Ciência da Informação e Documentação, Universidade de Brasília, Brasília, 2000.

RODRIGUES, E. Bibliotecas virtuais e cibertecários: o futuro já chegou. Portugal: Universidade do Minho, 1996. (mimeo).

TARAPANOFF, K. O profissional da informação em áreas de ciência e tecnologia no Brasil: características e tendências. Ciência da Informação, v.12, n.2, p.103-119, 1989. 
